\title{
Innovation as Determining Factor of Post-M\&A Performance: The Case of Vietnam
}

\author{
Quan Hoang Vuong ${ }^{1}$, Nancy K. Napier ${ }^{2} \&$ Donaldine E. Samson ${ }^{3}$ \\ ${ }^{1}$ Solvay Brussels School of Economics and Management, Université Libre de Bruxelles, Brussels, Belgium \\ ${ }^{2}$ College of Business and Economics, Boise State University, Boise, Idaho, USA \\ ${ }^{3}$ Graduate School, Stamford International University, Bangkok, Thailand \\ Correspondence: Quan Hoang Vuong, Centre Emile Bernheim, SBS-EM, Université Libre de Bruxelles, \\ Brussels 1050, ULB CP 114/03, F. D. Roosevelt 50, Brussels-1050, Belgium. E-mail: qvuong@ulb.ac.be
}

Received: July 13, 2013

Accepted: July 17, 2013

Online Published: August 20, 2013

doi:10.5539/ijbm.v8n18p25

URL: http://dx.doi.org/10.5539/ijbm.v8n18p25

\begin{abstract}
This research aims to communicate new results of empirical investigations to learn about the relationship between determination of controlling an acquired firm's capital, assets and brand versus its capability of innovation and ex post performance of Vietnam's M\&A industry in the 2005-2012 period. The analysis employs a categorical data sample, consisting of 212 M\&A cases, and performs a number of logistic regressions with significant results being reported on relationships between pre-M\&A strategic pursuit of innovation (versus capital/physical assets) of the acquired and post-M\&A performance. In addition, pre-M\&A capital expenditures tend to cause poor post-M\&A performance. As a general conclusion, this study shows that creative performance can be a factor to pursue in M\&A transactions, which suggests the need to emphasize capable and willing human capital. However, in a wave of M\&A where there is an overwhelming emphasis on assets and brands, the innovation factor's impact is limited.
\end{abstract}

Keywords: mergers and acquisitions, innovation/creativity, firm performance, economic transition, human capital, financial markets

\section{Introduction}

The birth of Vietnam's stock market has enabled researchers to better observe the emerging market economy in transition, where both universal trends and market anomalies can be detected using various methods of empirical data analysis, such as those previously reported by Farber \& Vuong (2004); Vuong (2010); Vuong, Tran \& Nguyen (2010); Vuong \& Tran (2010).

This research article focuses on mergers and acquisitions (M\&A) in Vietnam's emerging market economy from 2005 to 2012, when M\&A transactions value was estimated around US\$ 10 billion. Vietnam's re-integration into the world economy has not been without obstacles and difficulties (Stiglitz 2008). Since Vietnam's M\&As began in earnest during the post-WTO globalization process, it may be a signal for the complexity of the economy's next period of transition. In emerging markets, foreign transnational corporations (TNC) may pursue a strategy of taking over resources (capital/physical) and market positioning, partly defined by the brand strength of the acquired firm in a local market. The Vietnamese M\&A data for the 1990-2010 period shows that $79.4 \%$ of the M\&A attempts came from foreign firms acquiring domestic ones (Vuong, Tran \& Nguyen 2010).

Both acquiring and acquired firms seek economic benefits when entering M\&A agreements. Thus, M\&As involve changes and expectation of profit opportunities for the parties involved, as well as some level of innovation (Drucker 1986, p.81). However, as many sellers consider M\&A is a way to exit from their industries, with satisfactory gains, they are unlikely to initiate structural changes and innovations. The current trend may represent a shift in the economic function of local businesspeople from being entrepreneurs to more of capitalists. In fact, motivated to exit the industry, the selling entrepreneur shows her declining commitment to both the future of the acquired firm and any future innovation. Consequently, future innovation would likely be in the hands of the acquiring one. Presumably, this pursuit has to be decided ex ante.

\subsection{Literature Review}

Calderón, Loayza \& Servén (2004) show that M\&A have become a mainstream economic operation in today’s 
business world, going through six waves over the past century (Katz, Simanek \& Townsend 1997), with technological innovations behind the most recent M\&A wave starting in 2000s. In East Asia, the trend appeared in late 1980s, while the 1997 Asian financial turmoil also contributed to the emergence of a regional M\&A wave (Mody \& Negishi, 2000).

The Vietnamese M\&A industry has been closely connected to the surging FDI inflows (Lall, 2002), and become increasingly important in the 2005-2010 period (Vuong et al. 2010). As expecting short-term profits is unrealistic in a transition economy, acquiring firms tend to seek longer-term value (Focarelli, Panetta \& Salleo 2002; Öberg \& Holtström 2006), knowing that making strategic acquisitions may help to increase the acquiring firm's power to control assets and significant access to market opportunities. That way, acquiring firms may also be able to secure stable supplies of production materials in a foreign country. Beena (2007) shows that in India's innovation-oriented pharmaceutical industry post-M\&A firms are more efficient compared to their pre-M\&A operations.

Still, for M\&A transactions, the question about real economic efficiency, and especially innovation capability, has been left unanswered. This question is even more critical in a transition economy like Vietnam, as innovation is the very thing that is needed the most (Te Velde, 2001; Lall, 2002; Napier, Dang \& Vuong 2012). The absence of an ex ante pursuit of innovation could even render post-M\&A operation's viability questionable.

In reality, a singular goal of acquiring brands and valuable assets (capital/physical) may miss a key function of M\&A: facilitating trade liberalization and industrial restructuring. The high rate of success, approximately $90 \%$, for M\&A attempts in the 2005-2010 period in the Vietnamese capital market, shows how local enterprises embraced abundance of resources temporarily available to them following the sole 'serendipity' method for identifying emerging opportunities (Napier \& Vuong 2013). This over-reliance on capital and/or physical resources can become detrimental because the economy needs innovation capabilities and entrepreneurship (Napier et al 2012; Vuong \& Napier 2013b), especially in a transition economy like Vietnam, where entrepreneurial activities have been faced with socio-cultural obstacles (Vuong \& Tran 2009). The question on strategic pursuit of creative performance and innovations in an M\&A transaction is thus critical (Vuong \& Napier 2013a; Vuong, Napier \& Tran 2013; Vuong, Tran, Napier \& Dau 2013).

\subsection{Research Questions}

Reviewing the literature has led us to the crucial research questions as follows.

Q1: What do we learn about M\&A success/failure, given acquiring firm's focus on acquired firm's resources/brand versus its capability of technology/management innovation?

Q2: Is the absence of a strategic intent for acquired firm's innovation capacity likely to adversely affect post-M\&A performance?

Q3: Does "large capital expenditure" explain the failure of post-M\&A performance if innovation is not an intent from the beginning of the process?

Essentially, answering the above questions enables us to better understand the relationship between the acquiring firm's (absence of) strategic pursuit for acquired firm's innovation capacity and the business (and especially, financial) performance of the post-M\&A operation.

\section{Method and Data}

\subsection{Method of Research}

The paper employs the statistical analysis on categorical data. A rich account of statistical treatments for this type of analysis is provided in Agresti (2002) and Azen \& Walker (2011). Specific implementations of analytical methods and hypothesis testing can be referred to Napier, Dang \& Vuong (2012); Vuong \& Napier (2013b). Subsequent analyses perform various logistic regression estimations for dichotomous response variables and categorical predictor variables, having a general specification as follows:

$$
\ln [\pi /(1-\pi)]=\operatorname{logit}(\pi)=\beta_{0}+\beta_{i} X_{i}^{K}, i=1, \ldots K,
$$

where, $\pi$ represents the 'success probability,' that is when the performance of the post-M\&A operation satisfies the expectation by the acquiring firm (Perf=1). This event is observed directly from the empirical data set, where $\beta_{0}$ is the intercept, and the $\beta_{\mathrm{i}}$ coefficient associates with the $\mathrm{i}^{\text {th }}$ predictor variable, $\mathrm{X}_{\mathrm{i}}$.

For each categorical predictor variable, $X_{i}$, the standard null hypothesis is: $\mathrm{H}_{0}=\beta_{\mathrm{i}}=0, \mathrm{i}=1,2, \ldots, \mathrm{K}$. For examining interactions between variables, $\mathrm{H}_{0}$ becomes $\beta_{i} \beta_{j}=0, \forall i \neq j$. The statistic employed for hypothesis testing is the standard likelihood ratio measure, which is $\chi^{2}$-distributed: $G^{2}=-2 \ln \left(L_{0} / L_{1}\right)=-2\left[\ln \left(L_{0}\right)-\ln \left(L_{1}\right)\right] . L_{0}$ is the 
numerical value of the likelihood function computed from the observed data under the null hypothesis estimate $(\pi)$, and $L_{l}$ under the empirically evaluated estimate $\left(\pi^{*}\right)$. This $\mathrm{G}^{2}$ test statistic follows a $\chi^{2}$ distribution with $\mathrm{K}$ degrees of freedom (for detailed technical discussion, see Agresti 2002; Azen \& Walker 2011).

\subsection{The Empirical Data Set}

The data set employed in this research work consists of coded data points for 212 M\&A transactions in Vietnam from 2005 to 2012. Several structured data sets (Table 1,2) are tabulated with six distinct dichotomous categorical predictor variables, namely Expenditure, Technology Innovation, Management Innovation, Capital Resources, Physical Assets, and Valued Brand.

The binary response variable used to examine the theoretical hypotheses is post-M\&A performance ('Perf'; Perf $=1$ when positive performance is recorded 'Yes' and Perf $=0$ when 'No'). The data sets also consider qualitative information and insights from various formal reports published by Vietnam Stock Market authorities, listed firms, financial analyst groups, and local media sources like Dau Tu Chung Khoan, Vietnam Economic Times, Saigon Economic Times, to name a few.

In both table 1 and table 2, Inno1 means 'ex ante pursuit of innovation verified'; and Inno0 'not verified'. 'Yes' and 'No' are confirmation of efficient firm performance as observed with our empirical data, respectively. Brand1 means 'determined that the M\&A pursuit was dependent on brand value', Brand0 'Independent'. Likewise Res 1 and Res 0 are 'pursuit of capital and/or physical assets' and 'none', respectively.

Table 1. Contingency table for performance, innovation, resources and brands

\begin{tabular}{ccccc}
\hline & & Brand1 & Brand0 \\
\hline \multirow{3}{*}{ Yes } & \multirow{3}{*}{ Inno1 } & Res1 & 50 & 15 \\
& & Res0 & 2 & 2 \\
& \multirow{3}{*}{ Inno0 } & Res1 & 23 & 45 \\
& & & 0 & 0 \\
\hline \multirow{3}{*}{ No } & \multirow{3}{*}{ Inno1 } & Res1 & Brand1 & Brand0 \\
& & Res0 & 15 & 11 \\
& \multirow{3}{*}{ Inno0 } & Res1 & 1 & 1 \\
& & Res0 & 11 & 31 \\
& & & 3 & 2 \\
\hline
\end{tabular}

In what follows, the table 2 below splits 'Resources' into Physical Asset (with categories As1 vs. As0) and Capital (Cap1 vs. Cap0), while the remaining variable is 'Expenditure' which tells whether the M\&A is considered expensive or financially costly. This step enables us to later perform a deeper analysis on equation (4) relating to the presence of the so-called expensive capital expenditure in an M\&A pursuit.

Table 2. Contingency table for performance, expenditure, assets and capital resources

\begin{tabular}{lllcc}
\hline & & & Cap1 & Cap0 \\
\hline \multirow{3}{*}{ Yes } & Exp1 & As1 & 52 & 52 \\
& & As0 & 14 & 4 \\
& Exp0 & As1 & 5 & 10 \\
& As0 & & 0 & 0 \\
\hline \multirow{3}{*}{ No } & Exp1 & As1 & Cap1 & Cap0 \\
& & As0 & 18 & 33 \\
& Exp0 & As1 & 4 & 2 \\
& As0 & 4 & 3 \\
\hline
\end{tabular}


In both table 1 and table 2, the response variable 'Performance' takes value of either 'Yes' (i.e., 1) or 'No' (0), conditional upon other predictor variables values given in corresponding cells. These two tables of count data serve to be the input for subsequent logistic regressional analyses.

The next section discusses empirical results obtained from each specification's estimation.

\section{Results}

Estimations provided in the next discussion employ logistic regressions evaluated by SAS software. The model for assessing the goodness of fit is the standard global null hypothesis $\mathrm{H}_{0}=\beta_{1}=\beta_{2}=\ldots=0$, which yield corresponding likelihood ratio (LR) test statistic values, estimated from the empirical data set as given in table 1 and table 2 .

The first specification that is estimated is given by equation (1):

$$
\operatorname{logit}(\pi)=\ln [\pi /(1-\pi)]=\beta_{0}+\beta_{1} \text { Inno }+\beta_{2} \text { Res }+\beta_{3} \text { Brand },
$$

where the event to observe is 'positive post-M\&A performance'. The data set counts 137 entries. Results reported from this estimation confirm that $\mathrm{H}_{0}$ is rejected decisively at $5 \%$ level, with LR statistic and Wald statistic being 9.88 and 9.25 , respectively (with 3 degrees of freedom), leading both respective p-Values to be smaller than 0.05 .

Thus, this relationship is statistically meaningful. The analysis of Maximum Likelihood Estimates (MLEs) for estimation (1) follows.

Table 3. Analysis of MLEs for estimation of equation (1)

\begin{tabular}{|c|c|c|c|}
\hline Parameter & Estimate & Chi-square & p-Value \\
\hline Intercept $\left(\beta_{0}\right)$ & -1.0484 & 2.47 & 0.11 \\
\hline Inno $\left(\beta_{1}\right)$ & 0.3941 & 1.51 & 0.22 \\
\hline $\operatorname{Res}\left(\beta_{2}\right)$ & $1.3262 * *$ & 4.12 & 0.04 \\
\hline Brand $\left(\beta_{3}\right)$ & 0.4802 & 2.29 & 0.13 \\
\hline
\end{tabular}

Note: $(* *)$ Significant at $5 \%$ level.

From the reported results, it is noticed that only the 'Resources' variable has a significant explanatory power in this estimation.

The next statistical evaluation is performed on the following equation (2):

$$
\operatorname{logit}(\pi)=\beta_{0}+\beta_{1} \text { Res }+\beta_{2} \text { Brand, }
$$

where 'negative post-M\&A performance' is the event to observe (Perf $=$ 'No'). Empirical estimation shows that LR-statistic is $8.36(\mathrm{df}=2)$, rejecting $\mathrm{H}_{0}$ at $5 \%$ significance level. The analysis of MLEs shows that both 'Resources' and 'Brand' factors are found significant in this evaluation with their corresponding estimated coefficients being reported at -1.2923 and -0.6231 , respectively, leading to their corresponding p-Values of 0.048 and 0.035 . So both coefficients are statistically significant at $5 \%$ conventional level, with 1 degree of freedom $(\mathrm{df}=1)$.

Next we consider a relationship between negative post-M\&A performance and absence of ex ante plan on pursuit of innovation, given by equation (3):

$$
\operatorname{logit}(\pi)=\beta_{0}+\beta_{1} \text { Inno }
$$

The event to observe is Perf='No', where the reference category for the predictor variable is 'Inno1'. Estimated coefficients obtained from this estimation on empirical data and their reported significance are given in table 4 . 
Table 4. Analysis of MLEs for estimation of equation (3)

\begin{tabular}{lccc}
\hline Parameter & Estimate & Chi-square & p-Value \\
\hline Intercept $\left(\beta_{0}\right)$ & $-0.9019^{*}$ & 16.20 & $<0.0001$ \\
Inno $\left(\beta_{1}\right)$ & $0.5325^{* * *}$ & 3.29 & 0.0697 \\
\hline
\end{tabular}

Note: $(*, * *)$ Significant at $1 \%$ and $10 \%$ conventional levels, respectively.

The empirical estimation for specification (3) reports that both $\beta_{0}$ and $\beta_{0}$ are significant, but at different levels of statistical significance, specifically $1 \%$ and $10 \%$ respectively. From reported results, the 'absence of innovation' factor has shown a much stronger (negative) influence that decisively determines the poor performance of firms in their post-M\&A period.

From the table 2, with presence of substantial capital expenditure, the following equation (4) is estimated:

$$
\operatorname{logit}(\pi)=\beta_{0}+\beta_{1} \operatorname{Exp}+\beta_{2} \text { Cap }+\beta_{3} \text { Asset, }
$$

The event to observe is Perf = 'No', while there are signs of costly capital expenditure, strong ex ante pursuits of resources. The numerical value of the Wald statistic is reported at 9.55 (with 3 degrees of freedom), thus rejecting $\mathrm{H}_{0}$ at $5 \%$ level (p-Value being 0.0228 ). This estimation shows that the only significant coefficient is $\beta_{1}$, showing an evaluated value of -0.8196 , with reported $\mathrm{G}^{2}$ statistic value being 4.3 , statistically significant at $5 \%$ conventional level (p-Value being 0.0382).

\section{Discussion}

Overall, the relationship between pre-M\&A determination on acquiring resources (financial/physical) and the post-M\&A performance is statistically significant. Vietnam's data suggest some positive, and profound, effects of the 'size matters' strategy on firms' post-M\&A performance. So to speak, the Innovation factor has not had significant meaning in an overwhelming 'asset/capital acquiring pursuit' strategy.

In contrast, the over-emphasis on resources and brand value - at the time of the M\&A pursuit - is the major explanation of negative performance for the post-M\&A operations. Simultaneously, the absence of innovation as a predefined goal in the pre-M\&A period appears to have significant explanatory power for poor ex post performance. In addition, the previously reported statistics also confirm that a plan to pursue innovation in the pre-M\&A period tends to support positive post-M\&A performance.

Finally, when the M\&A involves costly arrangement or expensive investments (size, price or running costs), no matter how large the resources the post-M\&A firm may acquire, pre-M\&A expenditures tend to adversely affect the post-M\&A performance results. In light of this, innovation and creative performance can, therefore, be an important factor to pursue in M\&A transitions, which suggests the need to emphasize capable and willing human capital, rather than resources or existing values of corporate/goods brands. The empirical results have in general confirmed the role of innovation (and creative performance) as the determining factor for success of an M\&A transaction, especially had this factor entered the pre-M\&A planning process.

However, the reality has shown that in a wave of M\&A where there is an overwhelming emphasis on assets and brands, the innovation factor's impact is limited, to a large extent.

In fact, actual observations have indicated that acquiring firms tend to be impressed by acquired firms' market share, size of assets (including distribution system), capital base... Nonetheless, these factors are not sufficient to guarantee success in the post-M\&A phase, let alone the fact that the due diligence process focusing on these factors could be costly themselves. In contrast, innovation capability - be it technology, management or distribution - of the acquired firm has generally been ignored and substantially undervalued. To help address this, previous works such as Napier \& Vuong (2013), Vuong \& Napier (2012; 2013a); Vuong, Tran, Napier \& Dau (2013) have made theoretical and empirical attempts in suggesting ways to look into issues of bringing up creative performance and innovation in the industry, which are to a large extent relevant to the current consideration of post-M\&A performance.

\section{References}

Agresti, A. (2002). Categorical Data Analysis. Hoboken, NJ: Wiley. http://dx.doi.org/10.1002/0471249688

Azen, R., \& Walker, C. M. (2011). Categorical Data Analysis for the Behavioral and Social Sciences. New York, NY: Routledge.

Beena, S. (2007). M\&A in the Indian pharmaceutical industry: Nature, structure and performance. MPRA Paper, 
No. 8144.

Calderón, C., Loayza, N., \& Servén, L. (2004). Greenfield foreign direct investment and mergers and acquisitions: Feedback and macroeconomic effects. Policy Research Working Paper, No. 3192, World Bank.

Drucker, P. F. (1986). Innovation and Entrepreneurship. New York, NY: HarperCollins.

Farber, A., \& Vuong, Q. H. (2004). New empirical results on anomalies and herd behaviour: Vietnam stock market 2000-2004. Economic Studies (Vietnam), 44(9), 55-59.

Focarelli, D., Panetta, F., \& Salleo, C. (2002). Why do banks merge? Journal of Money, Credit and Banking, 34, 1047-1066. http://dx.doi.org/10.1353/mcb.2002.0054

Katz, J. P., Simanek, A., \& Townsend, J. B. (1997). Corporate mergers and acquisitions: One more wave to consider. Business Horizons, 40, 32-40. http://dx.doi.org/10.1016/S0007-6813(97)90023-9

Lall, S. (2002). Implications of cross-border mergers and acquisitions by TNCs in developing countries. $Q E H$ Working Paper Series, QEH-WPS88.

Mody, A., \& Negishi, S. (2000). The role of cross-border mergers and acquisitions in Asian restructuring. Washington, DC: World Bank.

Napier, N. K., Dang, L. N. V., \& Vuong, Q. H. (2012). It takes two to tango: Entrepreneurship and creativity in troubled times - Vietnam 2012. Sociology Study, 2(9), 662-674.

Napier, N. K., \& Vuong, Q. H. (2013). Serendipity as a strategic advantage? In Wilkinson, T. J. (Ed.), Strategic Management in the 21st Century (Vol .1, pp. 175-199). Santa Barbara, CA: Praeger/ABC-Clio.

Öberg, C., \& Holtström, J. (2006). Are mergers and acquisitions contagious? Journal of Financial Markets, 10, $342-361$

Stiglitz, J. E. (2008). Making globalisation work-The 2006 Geary Lecture. Economic and Social Review, 39, 171-190.

Te Velde, D. W. (2001). Policies towards foreign direct investment in developing countries. ODI Research Papers, London.

Vuong, Q. H. (2010). Financial markets in Vietnam's transition economy: Facts, insights, implications. Saarbrücken, Germany: VDM Verlag Aktiengesellschaft \& Co.

Vuong, Q. H., \& Tran, T. D. (2009). Cultural dimensions of the Vietnamese private entrepreneurship. The IUP Journal of Entrepreneurship and Development, 6(3/4), 54-78.

Vuong, Q. H., \& Tran, T. D. (2010). Vietnam's corporate bond market, 1990-2010: Some reflections. Journal of Economic Policy and Research, 6(1), 1-46.

Vuong, Q. H., \& Napier, N. K. (2012). Coffee filters and creativity: The value of multiple filters in the creative process. CEB Working Paper Series, No. 12-036, Solvay Brussels School of Economics and Management (Université Libre de Bruxelles).

Vuong, Q. H., \& Napier, N. K. (2013a). Anatomy of the 3D innovation production with the Cobb-Douglas specification. Sociology Study, 3(1), 69-78.

Vuong, Q. H., \& Napier, N. K. (2013b). Resource curse or destructive creation in transition turmoil. China-USA Business Review, 12(5), 486-493.

Vuong, Q. H., Napier, N. K., \& Tran, T. D. (2013). A categorical data analysis on relationships between culture, creativity and business stage: The case of Vietnam. International Journal of Transitions and Innovation Systems, 3(1) (in press).

Vuong, Q. H., Tran, T. D., \& Nguyen, T. C. H. (2009). Mergers and acquisitions market in Vietnam's transition economy. Journal of Economic Policy and Research, 5(1), 1-54.

Vuong, Q. H., Tran, T. D., Napier, N. K., \& Dau, T. H. (2013). Business education in the emerging economy of Vietnam: Twenty years of expectations, illusions, and lessons. In I. Alon, V. Jones \& J. R. McIntyre (Eds.) Innovation in Business Education in Emerging Markets (pp. 96-112). New York, NY: Palgrave Macmillan. 


\section{Copyrights}

Copyright for this article is retained by the author(s), with first publication rights granted to the journal.

This is an open-access article distributed under the terms and conditions of the Creative Commons Attribution license (http://creativecommons.org/licenses/by/3.0/). 